\title{
Features of seismicity in Xinjiang and its possible reason after the Yutian $M_{\mathrm{S}} 7.4$ earthquake, 2008*
}

\author{
Qiong Wang ${ }^{1, *}$ Haitao Wang ${ }^{1,2}$ and Aiguo Xia ${ }^{1}$ \\ ${ }^{1}$ Earthquake Administration of Xinjiang Uygur Autonomous Region, Urumqi 830011, China \\ ${ }^{2}$ Lanzhou Base of Institute of Earthquake Science, China Earthquake Administration, Lanzhou 730000, China
}

\begin{abstract}
The paper discusses quantitatively the influence of the Yutian $M_{\mathrm{S}} 7.4$ earthquake of March 21, 2008 and Wuqia $M_{\mathrm{S}} 6.9$ earthquake of October 5, 2008 on regional seismicity in Xinjiang, and explains primarily the possible reason of earthquake activity feature in Xinjiang after the Yutian $M_{\mathrm{S}} 7.4$ earthquake by analyzing the static Coulomb failure stress change produced by the Yutian $M_{\mathrm{S}} 7.4$ earthquake and Wuqia $M_{\mathrm{S}} 6.9$ earthquake, and the seismicity feature of $M_{\mathrm{S}} \geq 3$ earthquakes in the positive Coulomb stress change region of Kashi-Wuqia joint region, the central segment of Tianshan Mountain and Kalpin block. The result shows that the Yutian $M_{\mathrm{S}} 7.4$ earthquake of March 21, 2008, may encourage the Wuqia $M_{\mathrm{S}} 6.9$ earthquake of October 5, 2008, and the Yutian $M_{\mathrm{S}} 7.4$ earthquake and Wuqia $M_{\mathrm{S}} 6.9$ earthquake may change the seismicity state in the central segment of Tianshan Mountain, Kalpin block and Kashi-Wuqia joint region, and encourage the subsequent $M_{\mathrm{S}} \geq 3$ earthquakes.
\end{abstract}

Key words: static Coulomb failure stress change; earthquake activity feature; Yutian $M_{\mathrm{S}} 7.4$ earthquake; Wuqia $M_{\mathrm{S}} 6.9$ earthquake

CLC number: P315.5

Document code: A

\section{Introduction}

The earthquakes are not isolated, and have some relationship among the different events, so one event occurrence may change the seismicity state in the surrounding region. Under the uniform tectonic stress, some strong earthquake occurrence may lead to stress field redistribution in the seismogenic zone, and result in stress increasing in some areas, and stress reducing in the other areas. At the some time, some areas may slow down the seismogenic process because of stress decreasing (Zhao and Liu, 1987). Some researches show that the positive Coulomb failure stress change produced by the large earthquake encourages the subsequent moderate earthquake occurrence, and the negative one may postpone the earthquake occurrence (Stein et al, 1997; Deng and Sykes, 1997; Wan et al, 2003; Wang et al, 2007). Some researchers analyze quantitatively seismicity relationship in the different regions with the Coulomb failure stress change from the big events (Pol-

\footnotetext{
* Received 30 June 2009; accepted in revised form 10 September 2009; published 10 December 2009.

• Corresponding author. e-mail: wang_qiong00@yahoo.com.cn
}

litz, 2000; Hao et al, 2006). Some studies show that the static stress changes from previous earthquakes have a strong influence on the location, and presumably the timing, of subsequent seismicity, and future events generally will occur in the regions where the Coulomb stress has been enhanced by previous events over periods of minutes and decades, and seismicity can be strongly influenced by small changes in the static stress field, in condition that stress accumulate not only on the fault itself but also in a large region surrounding the fault prior to an earthquake (King and Bowman, 2003).

Some observational phenomena show that there exists seismicity increase beyond the traditional aftershock area after some big earthquakes. The possible reason is static stress change produced by mainshock and dynamic stress change by seismic wave (Brodsky et al, 2000; Protti et al, 1995). Susan (2007) proposed two explanations on the tectonic settings and stress level, (1) there are local zones of weakness, even small Coulomb failure stress change could trigger earthquake, or (2) there are zones of local stress concentration.

There occurred the Yutian $M_{\mathrm{S}} 7.4$ earthquake on March 21, 2008, in Xinjiang, and then occurred the Wu- 
qia $M_{\mathrm{S}} 6.9$ earthquake on October 5, 2008 in the Kashi-Wuqia joint region, which are $800 \mathrm{~km}$ apart. There occurred six $M_{\mathrm{S}} \geq 5$ earthquakes (not including the aftershocks of the Yutian $M_{\mathrm{S}} 7.4$ earthquake and Wuqia $M_{\mathrm{S}} 6.9$ earthquake) in the central segment of Tianshan Moutain and Kalpin block, Xinjiang, from the Yutian $M_{\mathrm{S}} 7.4$ earthquake to April, 2009, and the regional seismicity increases remarkably in the two regions (Figure 1).

According to the static dislocation theory in elastic half space and Okada's method (1992), the paper calculates the static Coulomb stress change on main fault plane in the central segment of Tianshan Mountain and Kalpin block produced by the Yutian $M_{\mathrm{S}} 7.4$ earthquake and Wuqia $M_{\mathrm{S}} 6.9$ earthquake, and then analyzes the seismicity state change of $M \geq 3$ earthquakes in the Kashi-Wuqia joint region, the central segment of Tianshan Mountain and Kalpin block before and after the Yutian $M_{\mathrm{S}} 7.4$ earthquake and Wuqia $M_{\mathrm{S}} 6.9$ earthquake, finally discusses the triggering on the Wuqia $M_{\mathrm{S}} 6.9$ earthquake due to the Yutian $M_{\mathrm{S}} 7.4$ earthquake, and the seismic activity in the central segment of Tianshan Mountain and Kalpin block from the two big events.

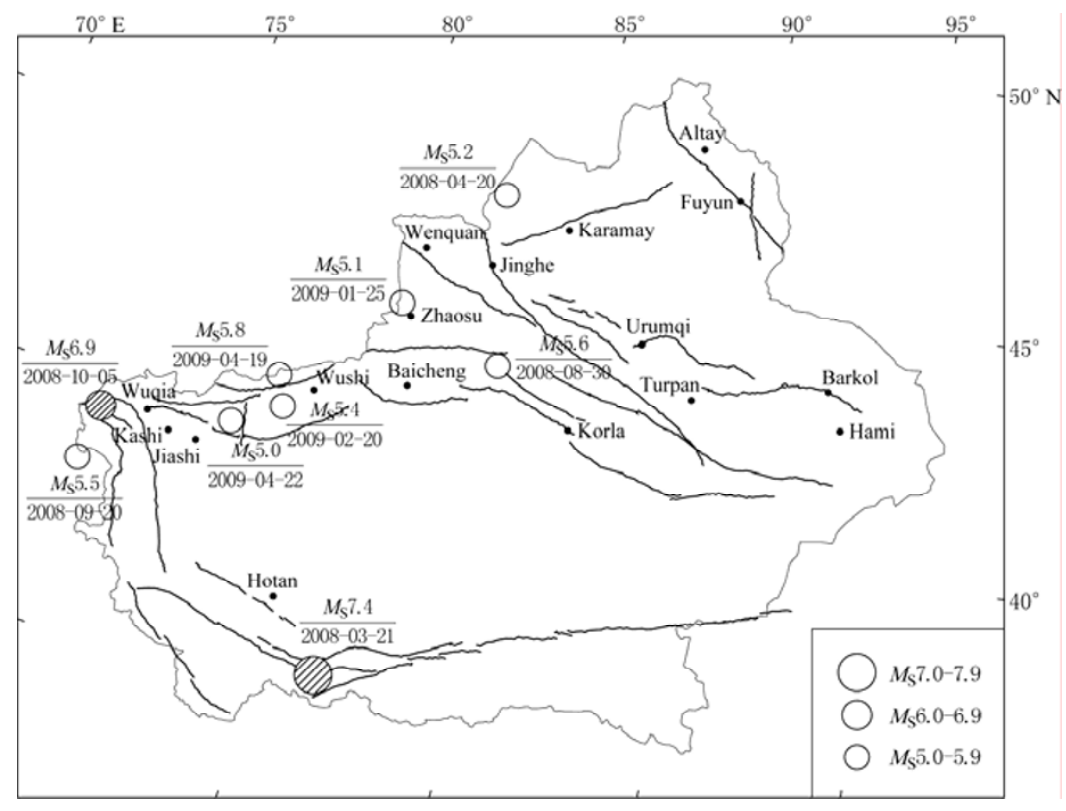

Figure 1 Map for the epicenter of Xinjiang $M_{\mathrm{S}} \geq 5$ earthquakes after the Yutian $M_{\mathrm{S}} 7.4$ earthquake of March 21, 2008.

\section{Method}

\subsection{Static Coulomb failure stress change}

According to the analytic expression fitting to all kinds of fault by Okada (1992), we calculate the static strain field caused by the earthquake, and then get the static stress field with Hook's law.

With the Coulomb failure criterion, Coulomb failure stress on the fault surface is defined as (Harris, 1998),

$$
\sigma_{\mathrm{f}}=\tau+\mu\left(\sigma_{n}+P\right)-S,
$$

$\tau$ is the shear stress on the fault surface, $\mu$ is the internal frictional coefficient, $\sigma_{\mathrm{n}}$ is the normal stress (positive tensile), $P$ is the pore fluid pressure, $S$ is the cohesion. Assuming the changes in $\mu$ and $S$ are negligible, the change in Coulomb failure stress is expressed as follows

$$
\Delta \sigma_{\mathrm{f}}=\Delta \tau_{\mathrm{s}}+\mu\left(\Delta \sigma_{\mathrm{n}}+\Delta P\right),
$$

where $\Delta \tau_{\mathrm{s}}$ is the change in shear stress, $\Delta \sigma_{\mathrm{n}}$ is the change in normal stress (positive for tensile), $\mu$ is frictional coefficient, $\Delta P$ is pore pressure change.

We assume an isotropic homogeneous material, and use an effective friction to simplify the unknown effects of fluid pressure, i.e., $\mu^{\prime}=\mu(1-B)$, where $B$ is Skempton's coefficient in the range of 0 and 1 . The equation (2) can be changed into

$$
\Delta \sigma_{\mathrm{f}}=\Delta \tau_{\mathrm{s}}+\mu^{\prime} \Delta \sigma_{\mathrm{n}} .
$$

$\mu^{\prime}$ value of 0.2 to 0.8 are widely used in some studies (Harris, 1998), the results are similar to other values of $\mu^{\prime}$ between 0 and 0.8 (Pollitz, 2006), we assume $\mu^{\prime}=0.4$ here.

With geometry parameter and dislocation of rupture plane, we may calculate the displace field and strain 
field.

The slip direction (strike, dip and rake) of the fault is from the focal mechanism solution, the geometry (length, width) and dislocation of the fault are calculated with the following experienced expression

$$
\begin{array}{ll}
M=3.54+2.08 \lg L & \text { (Huan et al, 1990), } \\
W / L=0.23 & \text { (Ding et al, 1993), } \\
D=L / \varepsilon, \varepsilon=(2.82 \pm 0.99) \times 10^{-5} & \text { (Ding et al, 1993), }
\end{array}
$$

where $M$ is magnitude, $L$ is fault length, $D$ is mean dis- placement and $\varepsilon$ is mean linear strain.

Table 1 lists the epicentral location, the geometry parameter and dislocation of the fault plane of the Yutian $M_{\mathrm{S}} 7.4$ earthquake and Wuqia $M_{\mathrm{S}} 6.9$ earthquake, the fault plane solutions are from the moment tensor solution of Harvard University, and we judge the rupture plane according to regional tectonic stress field and af-

\begin{tabular}{|c|c|c|c|c|c|c|c|c|c|c|c|}
\hline \multirow{2}{*}{ No. } & \multirow{2}{*}{ Date } & \multicolumn{2}{|c|}{ Epicentral location } & \multirow{2}{*}{$M_{\mathrm{S}}$} & \multirow{2}{*}{ Depth/km } & \multicolumn{6}{|c|}{ Fault plane parameters } \\
\hline & & Lat. $/{ }^{\circ} \mathrm{N}$ & Long. $/{ }^{\circ} \mathrm{E}$ & & & Strike ${ }^{\circ}$ & $\operatorname{Dip} /{ }^{\circ}$ & Rake/ ${ }^{\circ}$ & Length $/ \mathrm{km}$ & Width/km & Dislocation $/ \mathrm{m}$ \\
\hline 1 & 2008-03-21 & 35.81 & 81.44 & 7.4 & 33 & 203 & 52 & -74 & 71.7 & 16.5 & 2.02 \\
\hline 2 & 2008-10-05 & $39.46^{\circ}$ & $74.04^{\circ}$ & 6.9 & 10 & 77 & 47 & 97 & 41.2 & 9.5 & 1.16 \\
\hline 3 & Receiver fault & \multicolumn{4}{|c|}{$\begin{array}{l}\text { Main fault solution in the central segment of } \\
\text { Tianshan Mountain }\end{array}$} & 106 & 71 & 156 & & & \\
\hline 4 & Receiver fault & \multicolumn{4}{|c|}{ Main fault solution in Kalpin block } & 75 & 60 & 80 & & & \\
\hline
\end{tabular}
tershock distribution. In addition, we list the main fault plane solutions of the central segment of Tianshan Mountain and Kalpin block.

Table 1 Epicentral location and fault parameters of the Yutian $M_{\mathrm{S}} 7.4$ earthquake and Wuqian $M_{\mathrm{S}} 6.9$ earthquake and main fault solution of the central segment of Tianshan Mountain and Kalpin block

The paper first calculates the Coulomb failure stress change on fault plane of Wuqia $M_{\mathrm{S}} 6.9$ earthquake produced by the Yutian $M_{\mathrm{S}} 7.4$ earthquake, analyzes the seismicity state change of $M_{\mathrm{S}} \geq 3$ earthquakes in the Kashi-Wuqai joint region before and after the Yutian $M_{\mathrm{S}} 7.4$ earthquake; and then, by calculating the Coulomb failure stress change on the main fault surface in the central segment of Tianshan Mountain and Kalpin block, the article analyzes the six-month cumulative frequency change of $M_{\mathrm{S}} \geq 3$ earthquakes in the two regions since 2000 (deleting aftershocks), finally discusses the possible effect on the seismicity in the two regions resulting from the Yutian $M_{\mathrm{S}} 7.4$ earthquake and Wuqia $M_{\mathrm{S}} 6.9$ earthquake.

\section{Results and analysis}

Some results indicate that the effect distances by Coulomb failure stress change extend to several times the length of rupture zone. Earthquake activity increased clearly in some regions at distance up to $300 \mathrm{~km}$ from the epicenter several days to tens of days after the 1995 Hyogo M7.2 earthquake (Liu and Fu, 1999). The big earthquakes in Taiwan can trigger the medium earthquakes, and the remote triggering effect may be observed up to the distances of $3000 \mathrm{~km}$ on average (Wen et al, 1996). The M7.4 Izmit earthquake in 2001 triggered regional seismicity in Greece over a study region from 400 to $1000 \mathrm{~km}$ away from the epicenter (Brodsky et al, 2000). The 1992 M7.3 Landers earthquake triggered the seismicity at distances up to $1250 \mathrm{~km}$ (Hill et al, 1993).

According to above result, the paper discusses earthquake activity feature in the positive Coulomb failure stress change area at distance up to $1000 \mathrm{~km}$ after the Yutian $M_{\mathrm{S}} 7.4$ earthquake and Wuqia $M_{\mathrm{S}} 6.9$ earthquake, and tries to explain the possible reason of earthquake activity after the Yutian $M_{\mathrm{S}} 7.4$ earthquake.

\subsection{Triggering of the Wuqia $M_{\mathrm{S}} 6.9$ earthquake by the Yutian $M_{\mathrm{S}} 7.4$ earthquake}

Figure 2 is the Coulomb failure stress change on the receiver fault plane of the Wuqia $M_{\mathrm{S}} 6.9$ earthquake produced by the Yutian $M_{\mathrm{S}} 7.4$ earthquake. The Wuqia $M_{\mathrm{S}} 6.9$ earthquake locates in the positive Coulomb failure stress change area produced by the Yutian $M_{\mathrm{S}} 7.4$ earthquake (Figure 2), and the stress increase in the Kashi-Wuqia joint region is in the range of $0.1-0.3 \mathrm{kPa}$.

Figure 3 is the six-month cumulative frequency of $M_{\mathrm{S}} \geq 3$ earthquakes since 2000 in the region, the horizontal axis is year, and vertical axis is the $M_{\mathrm{S}} \geq 3$ earthquakes frequency with six-month window, $M_{\mathrm{S}} \geq 7$ earthquakes in Xinjiang and its surrounding region is in the square, the earthquakes with the magnitude of 5-6 occurred in the studied regions. The dashed line is the mean value of the six-month cumulative frequency of $M_{\mathrm{S}} \geq 3$ earthquakes in the region, i.e., the background value. It shows that seismicity of $M_{\mathrm{S}} \geq 3$ earthquakes since 2007 is higher than 21 times of the background value, and $M_{\mathrm{S}} \geq 3$ earthquakes increased once more after the Yutian $M_{\mathrm{S}} 7.4$ earthquake and before the Wuqia $M_{\mathrm{S}} 6.9$ earthquake (Figure 3). The 
Pakistan $M_{\mathrm{S}} 7.8$ earthquake on October, 2005, is about 1 $000 \mathrm{~km}$ from the Kashi-Wuqia joint region. The seismicity level of $M_{\mathrm{S}} \geq 3$ earthquakes is near to the background from 2000 to 2004, but the seismicity level is lower from 2005 to 2006, i.e., before and after the Pakistan $M_{\mathrm{S}} 7.8$ earthquake, and there are not $M_{\mathrm{S}} \geq 5$ earthquakes within the three years. The region locates in the negative Coulomb failure stress change area produced by the Pakistan
$M_{\mathrm{S}} 7.8$ earthquake (Wang and Gao, 2008). The above result indicates that the seismicity of $M_{\mathrm{S}} \geq 3$ earthquakes in the Kashi-Wuqia joint region may be related to the strong earthquakes in its surrounding region, and the Yutian $M_{\mathrm{S}} 7.4$ earthquake may change seismicity state in the region, and encourage the following moderate earthquake.

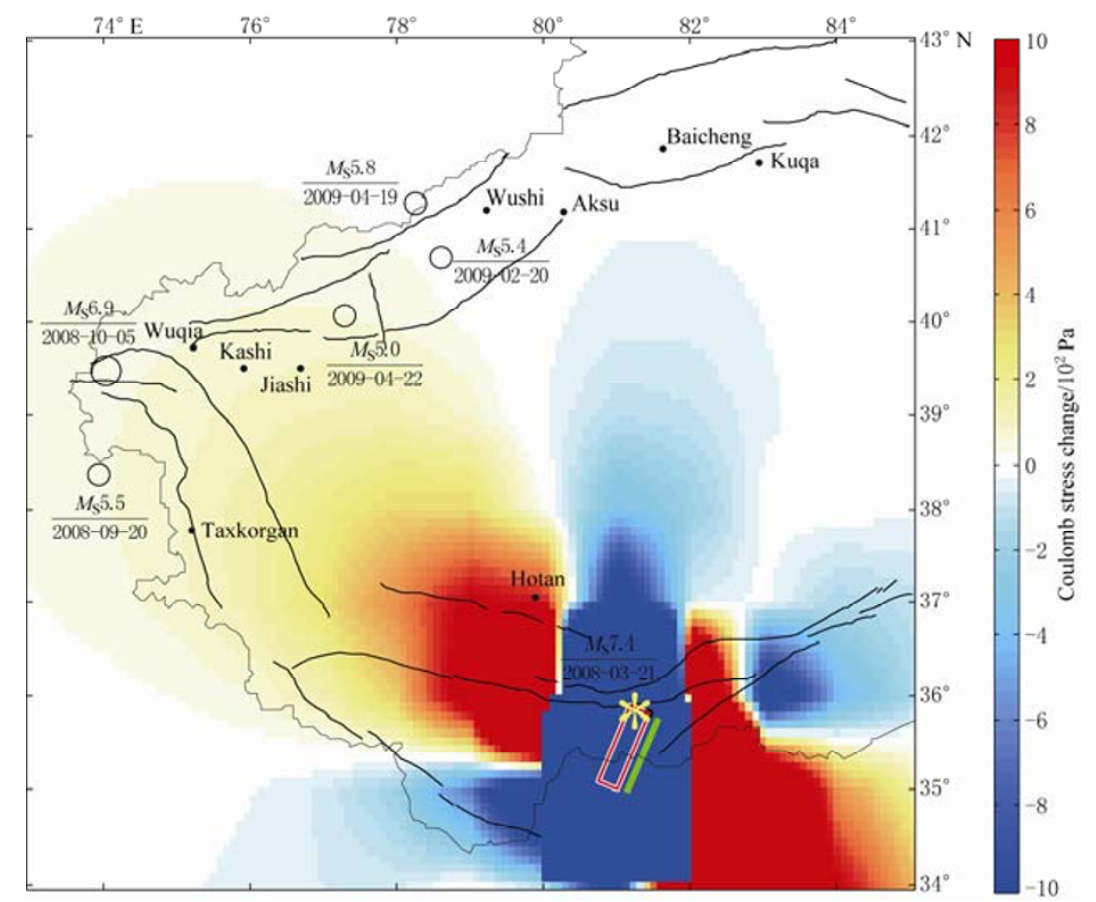

Figure 2 Coulomb failure stress change of the Yutian $M_{\mathrm{S}} 7.4$ earthquake (receiver fault is the rupture plane of the Wuqia $M_{\mathrm{S}} 6.9$ earthquake).

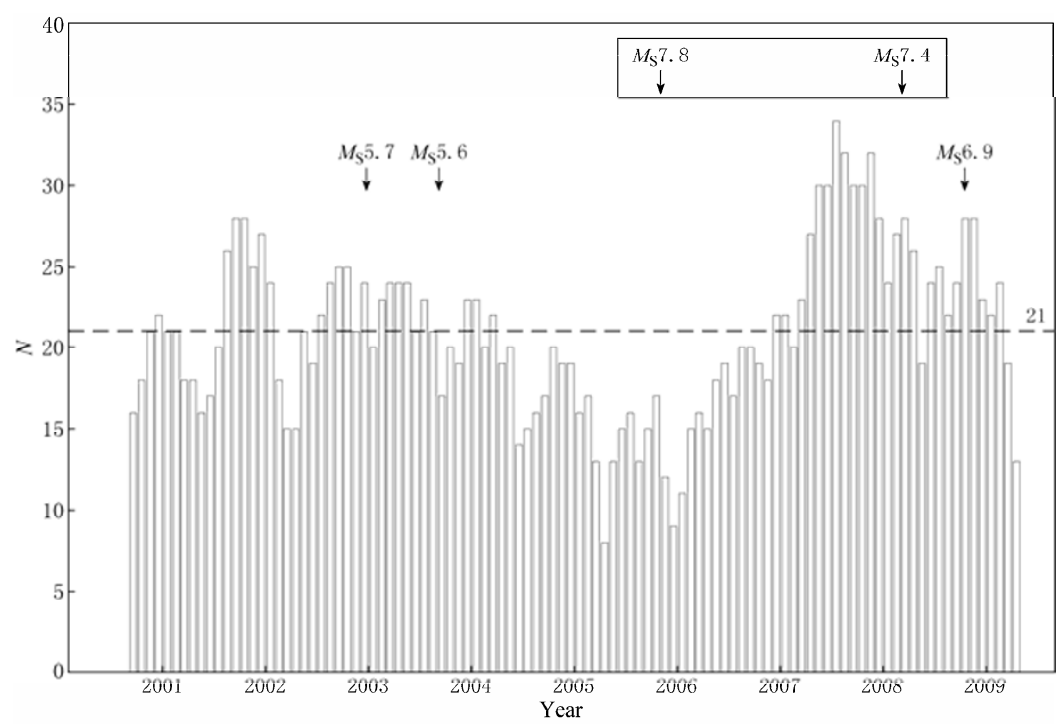

Figure 3 Six-month cumulative frequency of $M_{\mathrm{S}} \geq 3$ earthquakes in the Kashi-Wuqai joint region. 
3.2 Effect on the seismic ac tivity in the surrounding region due to the Yutian $M_{\mathrm{S}} 7.4$ earthquake and $\mathrm{Wu}$ qia $M_{\mathrm{S}} 6.9$ earthquake

\subsubsection{Yutian $M_{\mathrm{S}}$ 7.4 earthquake}

The Coulomb failure stress change on main fault plane in the central segment of Tianshan Mountain and Kalpin block by the Yutian $M_{\mathrm{S}} 7.4$ earthquake shows that the central segment of Tianshan Mountain (Figure 4a) and Kalpin block locate in the positive Coulomb failure stress change area (Figure 4b), and the stress increase in the central segment of Tianshan Mountain and the Kalpin block are both in the range of $0.1-0.2 \mathrm{kPa}$.

The six-month cumulative frequency of $M_{\mathrm{S}} \geq 3$ earthquake in the central segment of Tianshan mountain since 2000 shows that the seismicity of $M_{\mathrm{S}} \geq 3$ earthquake is higher than 23 times of the background value from April, 2007 to February, 2009, and the cumulative frequency is in the range of 27-30 times after the Yutian $M_{\mathrm{S}} 7.4$ earthquake, and two $M_{\mathrm{S}} 5$ earthquakes occurred during the period (Figure 5a). The seismicity of $M_{\mathrm{S}} \geq 3$ earthquakes since 2000 has increased for two times, there was $M_{\mathrm{S}} 7$ earthquakes in Xinjiang and its surrounding region during the period, which are about $1000 \mathrm{~km}$ from the region. The $M_{\mathrm{S}} \geq 3$ earthquakes increased obviously after the $2003 M_{\mathrm{S}} 7.9$ earthquake in the joint area of China, Russia and Mongolia, and the cumulative frequency is in the range of 30-35 times, there occurred the Zaosu $M_{\mathrm{S}} 6.0$ earthquake during the period. The $M_{\mathrm{S}} \geq 3$ earthquakes increased evidently after the 2005 Pakistan $M_{\mathrm{S}} 7.8$ earthquake, and the cumulative frequency is in the range of 27-39 times, there occurred the 2006 Wusu $M_{\mathrm{S}} 5.1$ earthquake. The central segment of Tianshan Mountain locates in the positive Coulomb failure stress change area by the $2003 M_{\mathrm{S}} 7.9$ earthquake and 2005 Pakistan $M_{\mathrm{S}} 7.8$ earthquake (Wang and Gao, 2008).

The six-month cumulative frequency of $M_{\mathrm{S}} \geq 3$ earthquakes in the Kalpin block since 2001 shows that the seismicity of $M_{\mathrm{S}} \geq 3$ earthquakes two months after the Yutian $M_{\mathrm{S}} 7.4$ earthquake is in the background level, then $M_{\mathrm{S}} \geq 3$ earthquakes increase remarkably, and the cumulative frequency is in the range of 12-18 times, which is far higher than nine times of the background value (Figure 5b). There occurred one $M_{\mathrm{S}} \geq 7$ earthquake in the surrounding of Xinjiang, about $1000 \mathrm{~m}$ from the region since 2001 , i.e., the 2005 Pakistan $M_{\mathrm{S}} 7.8$ earthquake. The seismicity level of $M_{\mathrm{S}} \geq 3$ earthquakes from 2003 to the three months before the Pakistan $M_{\mathrm{S}} 7.8$ earthquake is higher than the background, then is lower than the background till the end of 2006, and reaches to be lowest three months before and after the $M_{\mathrm{S}} 7.8$ earthquake, the cumulative frequency is less than 3 . The Kalpin block locates in the negative Coulomb failure stress change area by the 2005 Pakistan $M_{\mathrm{S}} 7.8$ earthquake (Wang and Gao, 2008).

The above result shows that the regional seismicity in the central segment of Tianshan Mountain and Kalpin block is related to the $M_{\mathrm{S}} \geq 7$ earthquakes in Xinjiang and its surrounding region, and strong earthquakes in the adjacent region. The Yutian $M_{\mathrm{S}} 7.4$ earthquake may change the seismicity state, and encourage the subsequent moderate earthquakes occurrence in the two regions. There occurred the Hejing $M_{\mathrm{S}} 5.6$ earthquake of August 30, 2008 and Chabuchaer $M_{\mathrm{S}} 5.1$ earthquake of January 25, 2009 in the central segment of Tianshan Mountain, three $M_{\mathrm{S}} 5$ earthquakes in Kalpin block from February to April, 2009.

\subsubsection{Wuqia $M_{\mathrm{S}} 6.9$ earthquake}

Kalpin block locates in the positive Coulomb failure stress change area of the Wuqia $M_{\mathrm{S}} 6.9$ earthquake and Yutian $M_{\mathrm{S}} 7.4$ earthquake, the stress increased in the Kalpin block by the Wuqia earthquake is in the range of 0-1 $\mathrm{kPa}$ (Figure 6a), and the cumulative stress increase by the Wuqia $M_{\mathrm{S}} 6.9$ earthquake and Yutian $M_{\mathrm{S}} 7.4$ earthquake is in the range of $0.1-1 \mathrm{kPa}$ (Figure $6 \mathrm{~b}$ ).

The six-month cumulative frequency of $M_{\mathrm{S}} \geq 3$ earthquake in the Kalpin block since 2001 shows that the seismicity of $M_{\mathrm{S}} \geq 3$ earthquake after the Yutian $M_{\mathrm{S}} 7.4$ earthquake and before the Wuqia $M_{\mathrm{S}} 6.9$ earthquake increased gradually, and increased sharply after the Wuqia $M_{\mathrm{S}} 6.9$ earthquake (Figure $5 \mathrm{~b}$ ), there occurred three $M_{\mathrm{S}} 5$ earthquakes within two months, i.e., from the February 20, 2009 to April 22, 2009 in the region (Figure 6).

\section{Discussion and conclusions}

The article discusses the triggering of the Yutian $M_{\mathrm{S}} 7.4$ earthquake and Wuqia $M_{\mathrm{S}} 6.9$ earthquake, and the effect on seismic activity in the central segment of Tianshan Mountain and Kalpin block due to the two earthquakes by calculating the static Coulomb failure stress change of the Yutian $M_{\mathrm{S}} 7.4$ earthquake and Wuqia $M_{\mathrm{S}} 6.9$ earthquake and analyzing seismicity state change of $M_{\mathrm{S}} \geq 3$ earthquakes in the Kashi-Wuqia joint region, the central segment of Tianshan Mountain and Kalpin block before and after the two events.

1) The Wuqia $M_{\mathrm{S}} 6.9$ earthquake on October, 2008, locates in the positive Coulomb failure stress change area 

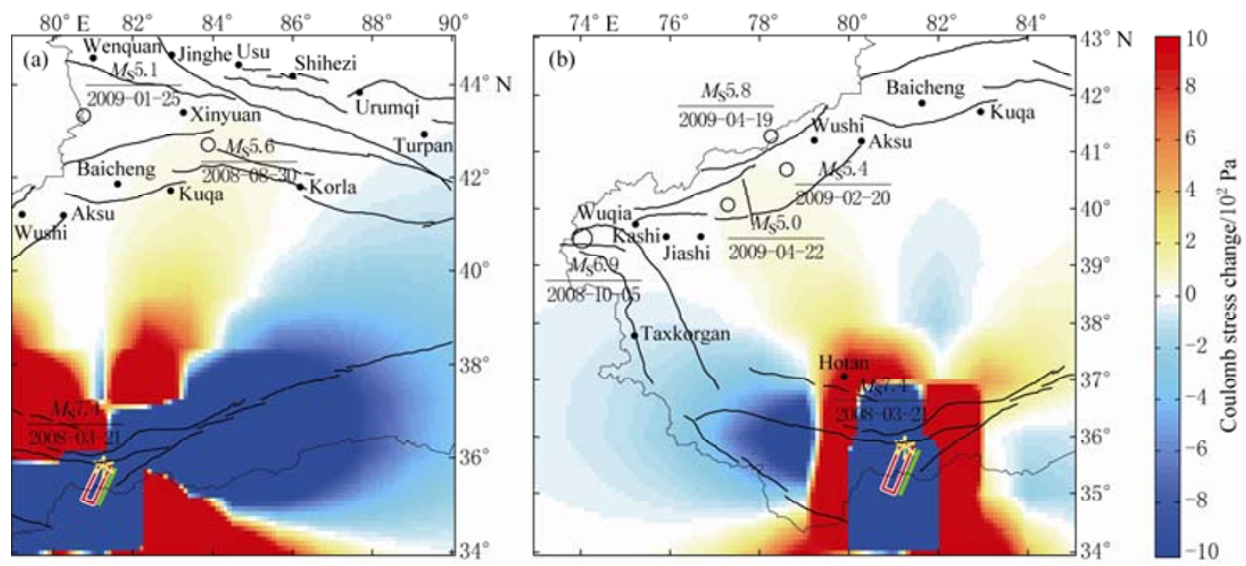

Figure 4 Coulomb failure stress change of the Yutian $M_{\mathrm{S}} 7.4$ earthquake. (a) The receiver fault is the main fault plane of the central segment of Tianshan mountain; (b) the receiver fault is the main fault plane of Kalpin block.
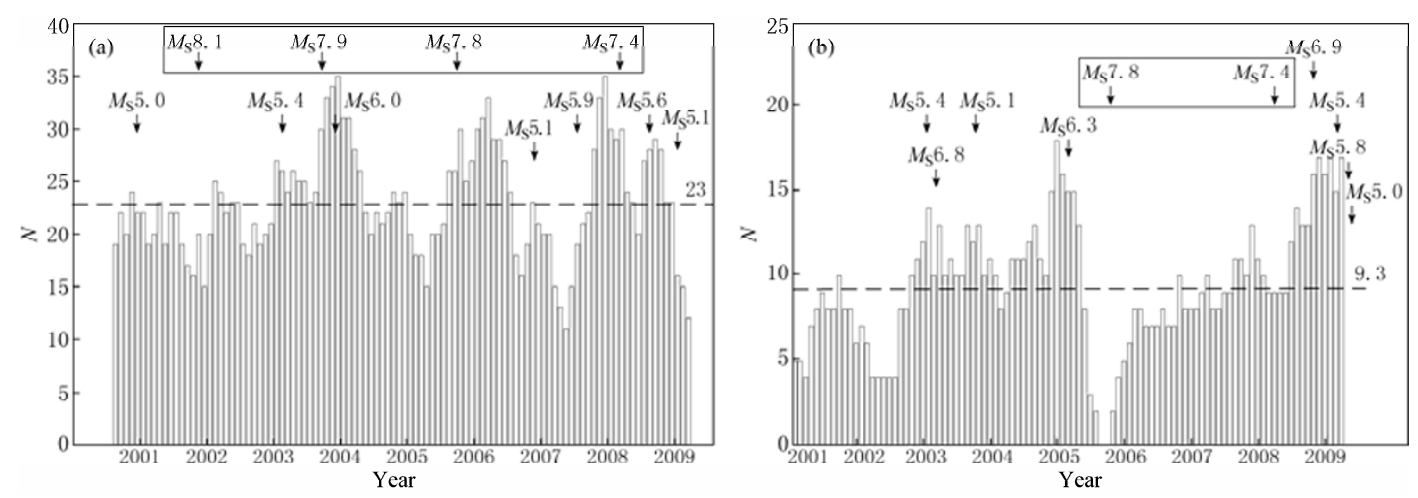

Figure 5 Six-month cumulative frequency of $M_{\mathrm{S}} \geq 3$ earthquakes in the different studied region. (a) The central segment of Tianshan Mountain; (b) the Kalpin block.
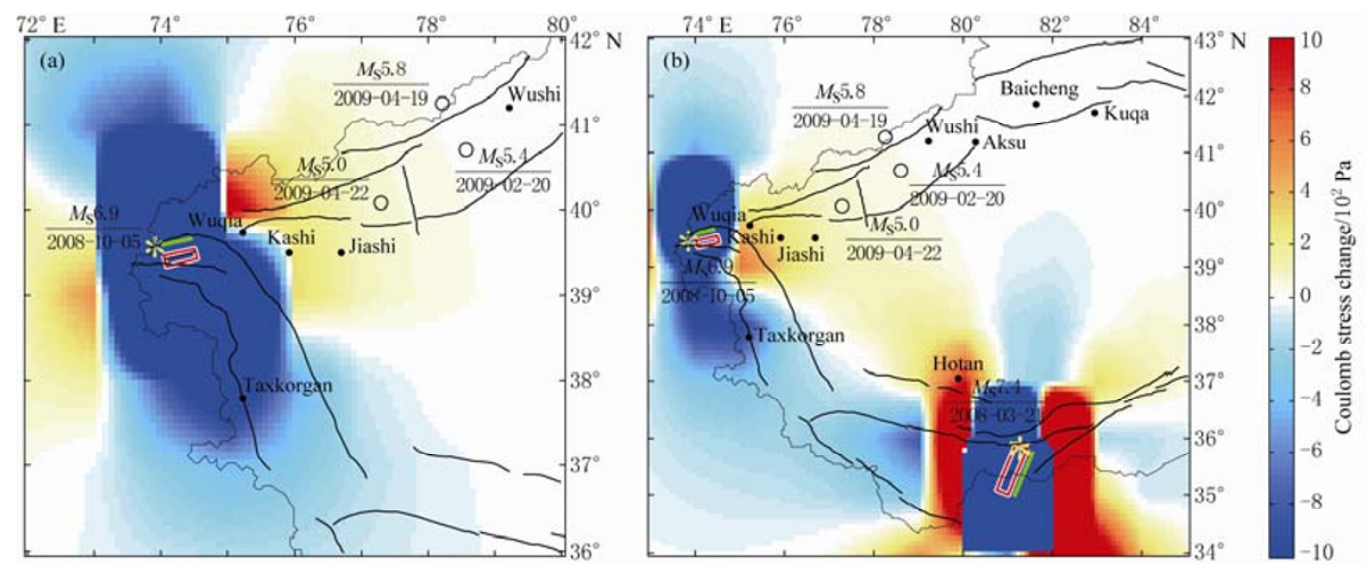

Figure 6 Coulomb failure stress change on the receiver fault of Kalpin block. (a) The Wuqia $M_{\mathrm{S}} 6.9$ earthquake; (b) the Wuqia $M_{\mathrm{S}} 6.9$ earthquake and Yutian $M_{\mathrm{S}} 7.4$ earthquake.

by the Yutian $M_{\mathrm{S}} 7.4$ earthquake, and the seismicity of $M_{\mathrm{S}} \geq 3$ earthquakes is higher than the background in Kashi-Wuqia joint region since April, 2007, and decreases rapidly two months after the Yutian $M_{\mathrm{S}} 7.4$ earthquake, and increases once more four months before the Wuqia $M_{\mathrm{S}} 6.9$ earthquake. The seismicity in the Kashi-Wuqia joint region may be related to the strong earthquakes in its surrounding region, and the Yutian $M_{\mathrm{S}} 7.4$ earthquake 
may encourage the subsequent moderate earthquake in the region with special tectonic and stress accumulation conditions.

2) The central segment of Tianshan Mountain locates in the positive Coulomb failure stress change area by the Yutian $M_{\mathrm{S}} 7.4$ earthquake. The seismicity of $M_{\mathrm{S}} \geq 3$ earthquakes in the region after the Yutian earthquake is higher than the background one, and $M_{\mathrm{S}} \geq 3$ earthquakes is active, which is similar to 2003 China-Russia-Mongolia $M_{\mathrm{S}} 7.9$ earthquake and 2005 Pakistan $M_{\mathrm{S}} 7.8$ earthquake.

3) The Kalpin block locates in the positive Coulomb failure stress change area by the Yutian $M_{\mathrm{S}} 7.4$ earthquake and Wuqia $M_{\mathrm{S}} 6.9$ earthquake. The seismicity of $M_{\mathrm{S}} \geq 3$ earthquakes in the region rises sharply after the Yutian $M_{\mathrm{S}} 7.4$ earthquake, and increases fast after the Wuqia $M_{\mathrm{S}} 6.9$ earthquake.

4) The Coulomb failure stress changes on the receiver fault produced by the Yutian $M_{\mathrm{S}} 7.4$ earthquake and Wuqia $M_{\mathrm{S}} 6.9$ earthquake in the range of $0-1 \mathrm{kPa}$. Could such magnitude of Coulomb failure stress change trigger the following moderate events? (1) The Wuqia $M_{\mathrm{S}} 6.9$ earthquake occurred about six months after the Yutian $M_{\mathrm{S}} 7.4$ earthquake, and the fault zones of the two events are linked. The Kashi-Wuqia region locates in the northeast of the Pamir arcuate structure, and is the joint region of multi-sets huge tectonic zones, and the tectonic motion is strong. In addition, there are no $M \geq 6$ earthquakes since 1993, which is longer than five years of the mean interval of $M_{\mathrm{S}} 6$ earthquake quiescence, and the local stress is in the accumulation state. With such tectonic and stress conditions, the small Coulomb failure stress change may lead to the regional seismicity increase in the Kashi-Wuqia joint region. (2) The seismicity level in the central segment of Tianshan Mountain is high, and the annual frequency of $M_{\mathrm{S}} \geq 5$ earthquake is 1.2. There are multi-sets of large faults in the direction of NW and EW in the region, and new tectonic motion is strong. Some research shows that there exists the regional stress increasing during the seismogenic process, and stress drop value of medium-small earthquakes may be higher than the background one of earthquakes with the same magnitude during the period. The stress drop values of $M_{\mathrm{S}} \geq 2.5$ earthquakes in the central segment of Tianshan Mountain since September, 2007 are higher than $3180 \mathrm{kPa}$ (Liu and Wang, 2009) of the background one of medium-small earthquakes with the same magnitude, and especially the stress drop value of $M_{\mathrm{S}} \geq 2.5$ earthquakes are evidently higher since August, 2008, in the range of $4000-10000 \mathrm{kPa}$, which indicates that the stress level in the region may be high during the period. (3) The cumulative stress increase in the Kalpin block by the Wuqia $M_{\mathrm{S}} 6.9$ earthquake and Yutian $M_{\mathrm{S}} 7.4$ earthquake is in the range of $0.1-1 \mathrm{kPa}$. The fault zones of Kalpin block and Kashi-Wuqia joint region are linked. The Kalpin block locates in the west segment of Southern Tianshan mountains, there are multi-sets of large NE faults in the region. There are no $M \geq 5$ earthquakes since 1994 in the east of Kalpin block, which is much longer than four years of the mean interval of $M_{\mathrm{S}} 5$ earthquake quiescence.

The stress drop values of $M_{\mathrm{S}} \geq 2.5$ earthquakes in the east of Kalpin block are evidently higher than the background one of $7150 \mathrm{kPa}$ (Liu and Wang, 2009) since May, 2008, in the range of $14000-18000 \mathrm{kPa}$, which indicates that the stress level in the region is higher during the period. The stress drop value of medium-small earthquakes in the central segment of Tianshan Mountain and Kalpin block appears increased remarkable, which are much higher than the background value.

With the stress accumulation and tectonic conditions, the small positive Coulomb failure stress change by the Yutian $M_{\mathrm{S}} 7.4$ earthquake and Wuqia 6.9 earthquake encourages the subsequent moderate earthquakes in the central segment of Tianshan Mountain and the east of the Kalpin block, which may advance them. Those may be one of the possible reasons that moderate earthquakes occur continuously in the two regions.

Acknowledgements The research was supported by the Joint Seismological Science Foundation of China (No.A07095) and Special Public Sector Research (No.20090804). We thank anonymous reviewers for the constructive reviews on the manuscript, and appreciate Dr Longquan Zhou for his help on the Coulomb3.1 software.

\section{References}

Brodsky E E, Karakostas V and Kanamori H (2000). A new observation of dynamically triggered regional seismicity: Earthquakes in Greece following the August, 1999 Izmit, Turkey earthquake. Geophys Res Lett 27(17): $2741-2744$.

Deng J and Sykes L R (1997). Evolution of the stress field in southern California and triggering of moderate-size earthquakes: A 200 -year perspective. $J$ Geophys Res 102: 9 859-9 886.

Ding G Y, Tian Q J, Kong F C, Xie X F, Zhang L R and Wang L P (1993). Active fault: Principle, Method and Application. Seismological Press, Beijing, 143 (in Chinese).

Hao P, Liu J and Han Z J (2006). Research on dynamic stress triggering of three subsequent moderately strong earthquakes in China mainland following the Indonesia $M_{\mathrm{S}} 8.7$ Earthquake. Earthquake 26(3): 26-36 (in Chinese with English abstract). 
Harris R (1998). Introduction to special section: Stress triggers, stress shadows, and implications for seismic hazard. J Geophys Res 103: 24 347-24 358.

Hill D P, Reasenberg P A, Micchael A, Arabaz W J, Beroza G and Brumbaugh D (1993). Seismicity remotely triggered by the magnitude 7.3 Landers, California, earthquake. Science 260: 1617-1 623.

Huan W L, Chang X D and Huang W Q (1990). Comprehensive Probability Method of Seismic Hazard Analysis. Seismological Press, Beijing, 9-41 (in Chinese).

King G C P and Bowman D D (2003). The evolution of regional seismicity between large earthquakes. J Geophys Res 108(B2): 2 096, doi:10.1029/ 2001JB000783.

Liu G P and Fu Z X (1999). Regional seismicity triggered by the 17 January 1995 M7.2 earthquake in the south of Hyogo county. Acta Seismologica Sinica 21(3): 250-257 (in Chinese with English abstract).

Liu X F and Wang Q (2009). Study on alarming technique and index of strong earthquake in the northwestern tectonic region. Research Report of the National Key Scientific and Technological Program in the eleventh five-year plan by Earthquake Administration of Gansu Province and Earthquake Administration of Xinjiang Uygur Autonomous Region, 165-167 (in Chinese).

Okada Y (1992). Internal deformation due to shear and tensile faults in a half-space. Bull Seism Soc Amer 82: 1018-1 040.

Pollitz F F and Sacks I S (2000). Stress triggering of the 1999 Hector Mine earthquake by transient deformation following the 1992 Landers Earthquake. Bull Seism Soc Amer 92: 1487-1 496.
Protti M, McNally K, Pacheco J, Gonzalez V, Montero C, Segura J and Brenes J (1995). The March 25, $1990\left(M_{\mathrm{W}}=7.0, M_{\mathrm{L}}=6.8\right)$, earthquake at the entrance of Nicoya Gulf, Costa Rica: Its prior activity, foreshocks and triggered seismicity. J Geophys Res 100: 20 345-20 359.

Stein R S, Barka A A and Dieterich J H (1997). Progressive failure on the North Anatolian fault since 1939 by earthquake stress triggering. Geophys J Int 128: 594-604.

Susan E H (2007). Remotely triggered earthquakes following moderate main shocks. The Geological Society of America, Special Paper 425: 73-86.

Wan Y G, Shen Z K and Gan W J (2003). Research on elastic stress triggering among the big earthquakes in the eastern Kunlun active fault zone. Northwestern Seismological Journal 25(1): 1-7 (in Chinese with English abstract).

Wang Q and Gao G (2008). Analysis of three strong earthquakes in Xinjiang periphery from 2001 to 2005 to the influence of Xinjiang earthquake tendency. Inland Earthquake 22(2): 123-128 (in Chinese with English abstract).

Wang Q, Wang H T and Zhao W M (2007). Possible reason for the quiescence of strong earthquake of Kashi-Wuqia region in recent years. Earthquake 27(2): 99-111 (in Chinese with English abstract).

Wen K L, Beresnev I A and Cheng S N (1996). Moderate magnitude seismicity remotely triggered in the Taiwan region by the large earthquakes around in Philippline Sea Plate. Bull Seism Soc Amer 86: 843-847.

Zhao G M and Liu X L (1987). Physical mechanism and precursor meaning of "inducing foreshock". Earthquake Research in China 3(Suppl.): 60-65 (in Chinese with English abstract). 